Sharif University of Technology
Scientia Iranica
SCIENTIA
I RAN ICA
http://scientiairanica.sharif.edu

Research Note

\title{
Improving facility management of public hospitals in Iran using building information modeling
}

\author{
A. Alvanchi* and A. Seyrfar \\ Department of Civil Engineering, Sharif University of Technology, Tehran, Iran.
}

Received 4 January 2018; received in revised form 12 September 2018; accepted 8 January 2019

\section{KEYWORDS}

Building information modeling;

Facility management;

Public hospitals;

Hospital building.

\begin{abstract}
Improving management of complex and congested facilities in hospital buildings is a potential point for both reducing money spent and enhancing quality level of the medical services provided in public hospitals of Iran. Although Building Information Modeling (BIM) is identified as an effective tool for improving Facility Management (FM), use of advantages it offers to the FM processes of hospitals has been neglected thus far in the country. To address this issue, this research aims to investigate the BIM capabilities and the supporting organizational structure of public hospitals in Iran which can help improve their FM processes. A comprehensive literature review of applicable capabilities of BIM to the FM processes was conducted. Hierarchical FM structure of public hospitals in the country was recognized through a review of the related regulations. A public hospital case was chosen for in-depth recognition of FM process operations and validation of the proposed BIM-based improvements. It was argued that the use of BIM capabilities could substantially improve the FM processes of public hospitals. Reduced duration of FM activities, improved facility layouts, enhanced communication and coordination, facilitated training, and improved emergency management are some of the expected outcomes.
\end{abstract}

(C) 2020 Sharif University of Technology. All rights reserved.

\section{Introduction}

Hospitals are complex organizations with various stakeholders, facilities, and materials closely linked and working together to accomplish their vital missions, i.e., curing patients in need and improving public health. The complex combination of people with different organizational roles and various types of materials and facilities working together with a variety of sensitive medical procedures makes operating costs of

\footnotetext{
*. Corresponding author.

E-mail addresses: alvanchi@sharif.edu (A. Alvanchi); abolfazl.seyrfar@gmail.com (A.Seyrfar)
}

hospitals the highest among the public service organizations [1,2]. As World Health Organization [3] reports, government expenditure on health exceeds $14 \%$ of total government's expenditure globally. Despite the high cost of different hospital operations, a single slight flaw in any parts of this complex organization may cause dire consequences and significant dissatisfaction. Therefore, attempts to improve different parts of hospital management with the aim of quality enhancement and cost reduction are invaluable to the society.

Meanwhile, a variety of medical and non-medical equipment pieces used in hospitals and the demand for diverse medical utilities and services make the utility systems of hospitals the most congested and complex utilities among public buildings [4]. Furthermore, the high pace of advances in medical equipment technolo- 
gies in recent decade compels hospitals to continually install new medical equipment to maintain their operability and competitiveness in this highly competitive market. Cost-effective modifications to the utility systems become necessary to support new medical equipment. Poor hospital Facility Management (FM), though, can add to the costs of these modifications. Prolonged activities, frequent disruption of regular hospital operations, and short or excessive supply of utility services are mere some of the instances that result from poor FM during new equipment installation and utility modification [5]. A proper FM not only considerably contributes to operational cost-effectiveness for hospitals, but also improves the quality of medical services provided.

According to Gallaher et al. [6], retrieving equipment specifications and its past records in the field of FM takes a considerable amount of time; expediting access to this information can improve FM performance. However, without a reliable tool, a considerable portion of valuable historical equipment records is lost or becomes difficult to access over the equipment's lifecycle $[6,7]$. Use of dependable information management infrastructure can considerably improve FM processes [8]. Meanwhile, research efforts have demonstrated that Building Information Modeling (BIM) expedites access to the building components information and assists the hospital FM team to promptly decide and respond to the problems occurred [9]. Research findings indicate that the operation and maintenance phases of constructed structures absorb major costs spent over their lifecycles [10,11]. Nevertheless, most BIM research studies have focused on applications of BIM in design and construction phases [12]. Identified capabilities of BIM make it a suitable tool applicable to various aspects of FM processes such as quality control, energy management, maintenance and repair, and equipment installation and supervision [5]. With this perspective, the large building structure and congested utility system components of hospitals and delicate services provided for them justify the efforts to properly apply BIM capabilities to improving FM processes in hospitals.

Annually about $6.6 \%$ of Iran's GDP is spent on healthcare and $40.4 \%$ of this amount is spent by the government, which constitutes $17 \%$ of the total annual governmental budget [3]. A major part of this budget is spent on 537 public hospitals, funded and managed by the government [13]. Despite the huge amount of money spent on public hospitals, level of satisfaction with the healthcare system in the country is still low. For example, the satisfaction level of $20.7 \%$ about hospitals was reported by Farzadi et al. [14] and $32.8 \%$ was reported by Maharlouei et al. [15]. Despite the reported capabilities of BIM to improve FM processes, no research study in Iran has incorporated BIM in the FM processes of hospitals. To respond to this shortfall, this research assessed the possibility of incorporating different capabilities of BIM in the FM processes of public hospitals in Iran. Next, Section 2 presents the research methodology and different steps taken in the research. Section 3 discusses different aspects of research efforts for using BIM in FM processes. Section 4 briefly introduces current hierarchical structure of public hospitals and the way it affects FM processes of hospitals. Section 5 presents an in-depth recognition and analysis in the Public Hospital case of Hasheminejad, Tehran, Iran. Section 6 shows the recommended implementation architecture that supports the proposed BIM-based FM processes of the public hospitals in Iran. Section 7 concludes the research.

\section{Methodology}

The research was conducted in five main steps. First, a comprehensive literature review of various advantages and disadvantages identified for using BIM in FM processes was performed. In parallel to the first step, the hierarchical structure of public hospitals and the way it affects the FM processes in these hospitals in Iran were recognized. The case of Hasheminejad Public Hospital in Tehran, Iran is analyzed in step three to recognize operational details of FM processes in a sample public hospital. In step four, various BIM capabilities in FM processes were analyzed and the capabilities found suitable for the current situation of the hospital were proposed. A pilot implementation, then, was conducted to verify the applicability and suitability of the proposed modifications in connection with the FM crew in the hospital. Finally, in step five, a supporting architecture for implementation of the proposed improvements in public hospitals was recommended. The proposed recommendations were based on the current implementation methods found in the literature and the current condition of the FM processes in the public hospitals in Iran. Figure 1 summarizes different steps taken in the research.

\section{Use of BIM in FM processes}

FM is defined by the International Facility Management Association [16] as "the practice of coordinating the physical workplace with the people and work of the organization; it integrates the principles of business administration, architecture and the behavioral and engineering sciences". Working commission on management and maintenance of facilities in the international council for research and innovation in building and construction (CIB) considers four main scope areas of FM. These scope areas include financial management, space management, operational management, and be- 


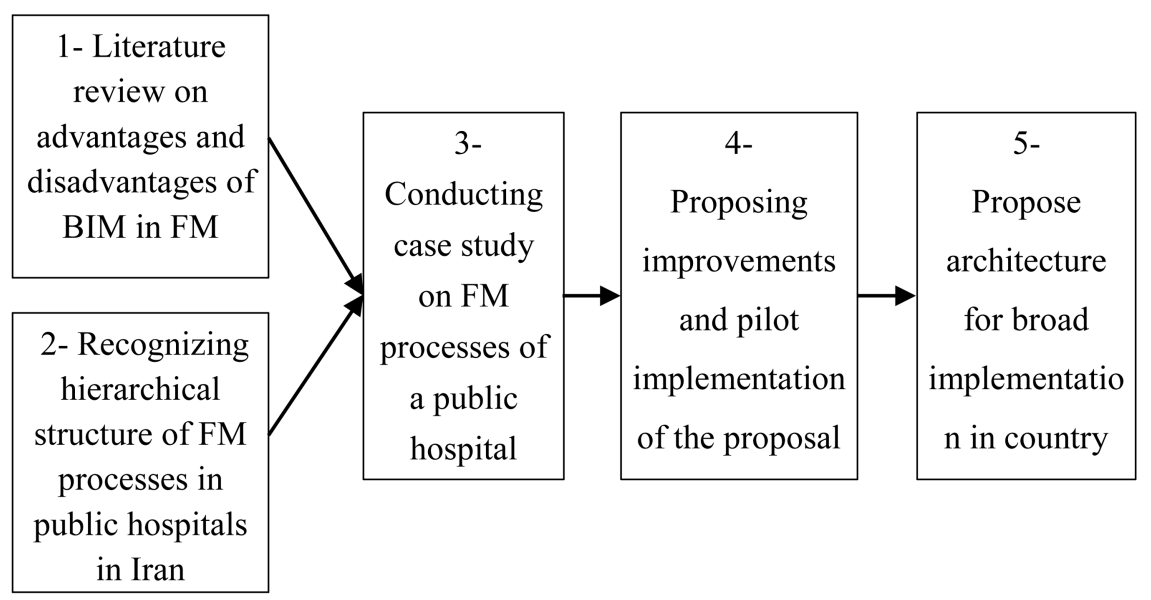

Figure 1. Different steps of the research.

havioral management [17] which cover a wide range of activities for FM during the operation phase of a building. From this perspective, in hospital buildings with complex medical services provided during the operation phase, FM is the key support for the sensitive medical procedures performed. Facility managers need to handle and utilize a broad range of information on the buildings, operations, equipment, patients, and employees [18]. A comprehensive literature review of the FM of the hospitals by Yousefli et al. [19] identified the use of information technology as the main trend in the recent research for developing cost-efficient and reliable FM processes. Here, BIM is seen as the main platform for facilitating the communication and maintenance of the information [19].

In many past research efforts, the identified potential applications of BIM were tested, analyzed, and improved. Implementation challenges of BIMbased FM were also reported. Among a variety of constructed structures, incorporation of BIM in FM of public buildings, e.g., educational building [20,21], city hall complex $[22,23]$, and hospital $[4,9,18,24-26]$, has been followed the most. Here, different benefits and challenges of using BIM in FM processes were reported. It was reported that use of BIM could improve FM processes in multiple directions including:

1. Shortening work order durations;

2. Analyzing multiple possible modification scenarios through three-dimensional models of buildings;

3. Facilitating the training process of various FM stakeholders;

4. Aanalyzing emergency conditions;

5. Facilitating real-time data access by storing equipment maintenance history on model;

6. Attaching statutory compliance data and work standards;
7. Controlling and monitoring energy.

Despite numerous benefits reported, past research [27-29] found BIM applications in FM still at the initial and emerging stages and encouraged further research to address the existing implementation challenges. Challenges found in these research efforts for incorporation of BIM in FM can be summarized as follows: absence of a structured method for incorporating BIM in FM processes; lack of proper tools for demonstrating BIM benefits to FM; limited knowledge on types of information to be collected and on the methods and tools used for applying BIM in FM; too many detailed specifications required for BIM development; lack of expertise in working with BIM in public organizations; resistance to changing the previously adopted methods; and challenges in linking BIM to the current tools used in FM. Furthermore, the past research on incorporation of BIM in FM processes of hospitals was mainly focused on single hospital cases rather than a network of hospitals. To address the existing gaps and challenges, this research aimed to propose an implementation method for BIM-based FM processes for the networks of public hospitals in Iran while the existing technological and organizational challenges are taken into account.

The global acceptance of BIM as an efficient tool for managing different phases of the building project lifecycle has urged developing an open data format interoperable among various contributing disciplines. The Industry Foundation Classes (IFCs) developed by building SMART, a non-profit organization, aimed to create this open file format [30]. Since 2013, the IFC has become an international standard of ISO 16739 for data sharing in the construction and FM industries [31]. Currently, IFC is supported by the majority of BIM software applications and it is considered as the main file format in the development of the BIM-based FM processes [32,33]. Gathering 
specifications of the information items in different parts of the BIM models is another challenging aspect of the development of the BIM-based FM processes. The Construction Operations Building Information Exchange (COBIE) [34] is a major step taken to define standard information items applicable to BIM-based models of FM processes. The COBIE has a lifecycle view to the integration of BIM and building projects with regard to the design, construction, and operation and maintenance phases. Ever since, the COBIE has become a standard information items structure in many developed BIM-based FM processes (e.g. [35-37]).

Proper setup of a $3 \mathrm{D}$ model is the initial step in employing BIM in FM processes. New 3D model development is required when BIM-based FM processes are applied to existing buildings with no 3D model available. The 3D model development of such buildings starts with collecting their spatial data using either existing as-built 2D drawings [38], direct measurement and observation, or new technologies such as laser scanning and photogrammetry [39]. Initial spatial data are processed to form a 3D model with meaningful objects [40]. Gradually, a variety of information cases required for FM are embedded within the object-oriented BIM model, making the BIM cloud accessible to different FM contributors [39]. Here, a major challenge is capturing the spatial data of various concealed building components adapted during the building's operation phase [41]. Setting up proper security management is required to ensure that the right people will access data under appropriate circumstances [42]. Proper security management is also required to avoid different project contributors that lose interest in incorporating their related data into the BIM cloud [43]. Facilitated access to various building components is one of the major capabilities of BIM-based FM processes. To improve this capability, BIM models benefit from new technologies such as mobile augmented reality [44], Radio Frequency Identification (RFID) tags [45], and even smartphones and tablets [46].

\section{FM structure of public hospitals in Iran}

Before identifying the operational details of FM processes in the public hospitals, a holistic view of the hierarchical structure and current condition of FM processes in public hospitals was obtained. Related regulations and references were studied and discussed with the people working in the public healthcare system. The healthcare system in Iran has a unique hierarchical structure. In this structure, medical universities, under supervision of the Ministry Of Health and Medical Education (MOHME), are responsible for providing health services, managing public hospitals, monitoring the private sector, and conducting medical research and education [47]. The dean of a medical university is the highest authority for all public hospitals in a specified geographical area, e.g., a province, and the dean must report to the MOHME [48]. About $75 \%$ of Iran's hospital beds are in the public hospitals owned by MOHME, $16 \%$ are owned by other governmental bodies, and only $9 \%$ of them are privately owned [49]. It was estimated that more than $50 \%$ of hospitals in the country were worn out, many of which were poorly maintained [50], resulting in high maintenance and repair costs. Public hospitals are highly demanded because of their low medical service prices [51], leading to high deterioration rates. Considering that MOHME owns public hospitals and has responsibility for making health-related policies, it has recently enforced Public Hospitals to input all maintenance expense data to a web-based Computerized Maintenance Management System (CMMS). According to the estimates, this new system has reduced $40 \%$ of the life cycle costs of physical resources in public hospitals [52].

\section{Case study: FM processes of Hasheminejad Public Hospital}

This study investigated the case study of Hasheminejad Public Hospital, which enjoys an area more than 12,000 square meters and 151 active beds in Tehran. In this case study, different aspects of FM processes in public hospitals were recognized and the potential points of improvement BIM can make to FM of Public Hospitals were identified. This hospital was selected among several available choices because of its reputation in its organized FM and effective implementation of MOHME's new CMMS. Hasheminejad Hospital is a relatively old hospital since 1957 . In 1985, it became a national center for treating kidney diseases. Then, different steps taken in this case study were explained.

\subsection{Recognizing the FM processes}

Initial interviews with FM crews including medicalfacility manager, facility maintenance supervisor, and three members of facility maintenance team were conducted to draw an overall view of the hospital's FM process. Then, available FM documents of the hospital including mission and policy statement, code of conduct, manual of procedures, and instructions were reviewed. Finally, different parts of the FM processes and operations were closely observed in the two-week shadowing period. Recognitions achieved during the case study were presented into two parts: FM organizational structure and main FM processes.

\section{- The hospital's FM organization}

The main organization of FM team in the Hasheminejad Hospital is comprised of the medical equipment section and the Mechanical, Electrical, and Plumbing (MEP) section. The FM team consists of 12 crew members including oxygen supplier, 
construction manager, powerhouse team, electrician team, sewage treatment plant, welder, plumber, secretary, and the head of the team. The main organizational duties of the FM team are divided into five main categories including preventive maintenance and periodic inspection, calibration and quality control of equipment, repair of ruined or damaged equipment and facilities, managing changes in hospital spaces, facility procurement, and installment of medical equipment and facilities;

\section{- Main FM processes}

Duties assigned to the FM team were carried out through five main complementing processes interacting with four stakeholders outside the team including hospital manager, maintenance contractors, hospital personnel, and Iran Medical University.
The main five work processes identified through the FM process were:

1. Conducting periodical inspections;

2. Report evaluation;

3. Performing repair and maintenance works;

4. Procurement;

5. Performance report preparation.

Data Flow Diagram (DFD) was used as the main recognition tool in this research. It is a powerful tool for capturing and structurally summarizing the recognition achieved from different parts of the FM process. Figure 2 presents the DFD diagrams that show a holistic view of the entire FM processes and internal data interactions of the sample Public Hospital. A brief explanation of each process will be given below.

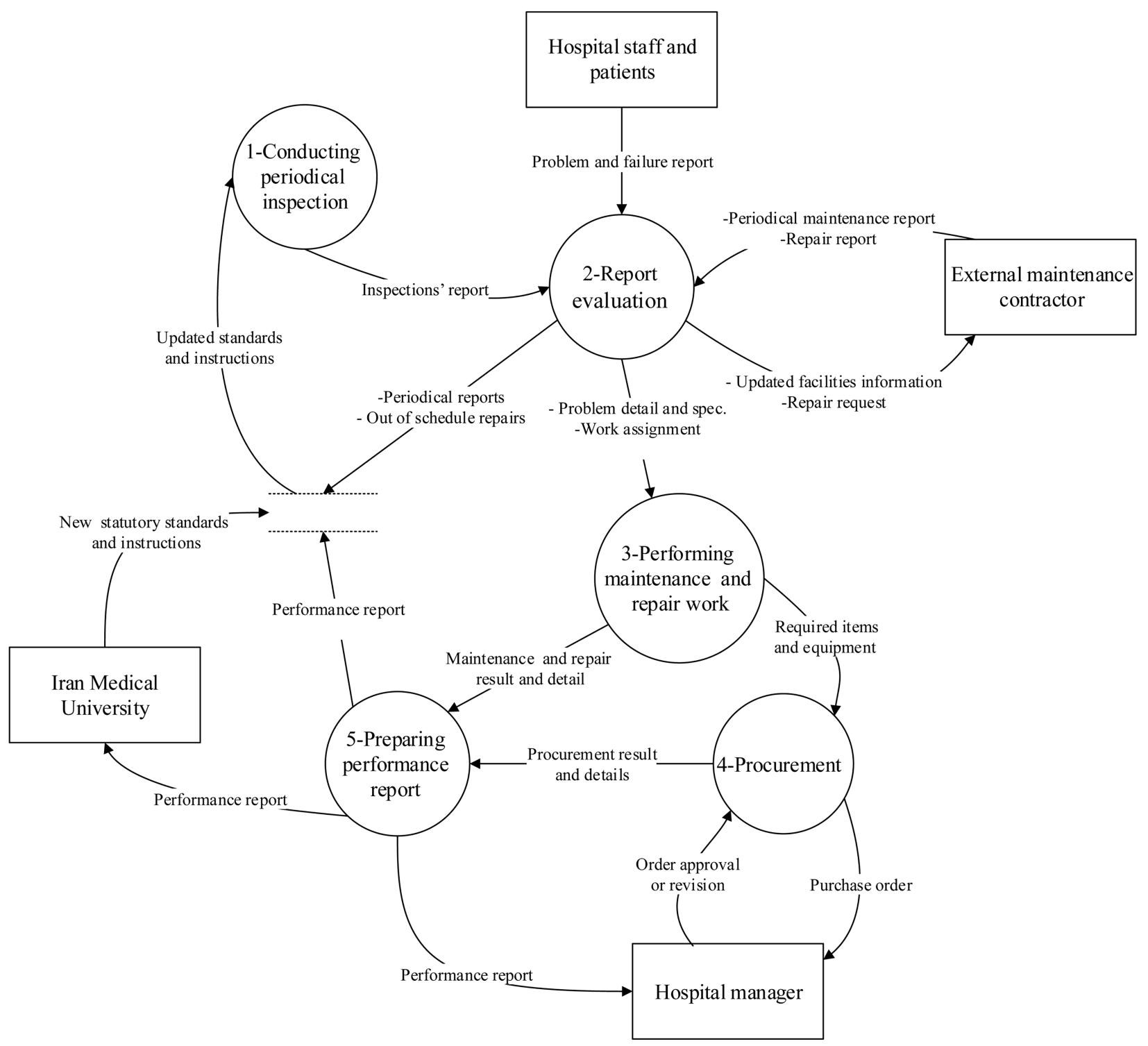

Figure 2. Data flow diagram level one of Facility Management (FM) processes of Hasheminejad Hospital. 
In the first process of FM, i.e., conducting periodical inspection, the FM team inspects and monitors MEP facilities and medical equipment in specified periods in accordance with the standard and/ or instructions set by Iran Medical University. All periodical inspections performed are reported to the University in paper forms. In the second process, report evaluation, reports prepared by FM team and external maintenance contractors, as well as the requests received from other hospital personnel are carefully read and evaluated. Further actions, e.g., maintenance and repair activities required, are determined based on their priorities and constraints. Subsequently, in the third process that involves performing maintenance and repair work, activities assigned to the related FM team crew are conducted according to the prepared schedule. A list of items concerning maintenance and repair required for completing maintenance and repair activities is prepared. In the procurement process, the price of the required items is reported to the hospital manager to receive his approval. Then, items are purchased and sent to the FM team to complete the maintenance and repair activities. In the fifth process, i.e., performance report, various maintenance, repair, and procurement activity reports are prepared in the form of performance reports and are sent to the Iran University of Medical Sciences and the hospital manager. It should be noted that different parts of the FM processes explained here and presented in the form of the DFD in Figure 2 represent the specific condition of the sample public hospital in Iran. Hospitals in other countries can benefit from these processes. Separate recognition steps need to be undertaken in such cases.

\subsection{Analyzing capabilities of BIM}

The applicability of different capabilities of BIM, identified in the literature $[5,10,24,39]$, was analyzed based on the recognition obtained from different parts of the FM. The created BIM maturity matrix [53] represented a low level of BIM maturity of the hospital's organization. Furthermore, three main constraints and requirements with respect to the BIM capabilities are given below:

- Forcing minimal changes to the existing organization to receive minimal resistance from the personnel;

- Minimal money investment to be considered as a result of limited public budget;

- Minimal academic engineering background to be supposed for the FM team members, since most of them have practical experiences rather than formal engineering training. From this perspective, FM crew should not account for BIM model development and maintenance.
MOHME required hospitals to maintain the most updated as-built hospital drawings. In the case of Hasheminejad Hospital, since FM team member was not able to update 2D drawing, the hospital manager hired an engineering consulting company five years ago to update the 2D drawings. The hospital's architectural, structural, and utility systems were updated based on the old drawings and FM team input. Ever since, however, FM team has not updated the modifications made to the hospital building. Therefore, the first modification made to the hospital FM processes was to develop BIM-based models of the hospital building rather than 2D CAD models. The drafting or consulting company hired for preparing the BIM model needs to stay linked to the hospital for the periodical (semiannual or annual) updates based on the modifications made to the hospital building over time. It is expected that following the development of the initial BIM models, updating BIM-based models costs less than the 2D model updates.

Recommendations for adoption or rejection of different BIM capabilities in the FM processes of public hospitals were made concerning the identified constraints and requirements. Our analysis of adoption or rejection of different capabilities of BIM resulted in recommending six capabilities of BIM to be incorporated for improving the FM process. Recommended capabilities include:

1. Locating building components;

2. New equipment layout and installation management [5];

3. Coordination of FM staff [39];

4. Communication with medical and other nontechnical personnel [4];

5. Training contractors and personnel [5];

6. Emergency management [54].

For all recommended capabilities, it was considered that minimal money investment and organizational changes imposed on the hospital and FM crew could manage them by attending short training sessions. The rejected capabilities include:

1. Storing equipment maintenance history;

2. Attaching statutory compliance data and work standards [28];

3. Controlling and monitoring energy using BIM [55].

Implementation of these capabilities required either holding intensive training sessions for current FM team members or hiring new FM crew with a proper level of education. Furthermore, money investment should be made to equip the hospital with new computer hardware and software. A brief explanation of how 
the recommended capabilities can improve the FM processes and their implementation methods is provided below:

\section{- Locating building components}

Currently, the FM team members depend on their memories for locating buried facilities. They have difficulties reading separated $2 \mathrm{D}$ drawings of the hospital building's architectural, structural, and utility systems, which is an error-prone, timeconsuming, and costly process. In some cases, the FM team was forced to cut walls, floors, and ceilings to locate the facilities. For example, as per FM team member explained, mistakes made in locating the exact location of the air ducts caused the construction of a new washroom unit in the ICU sector to cease. Figure 3 shows another example of the demolition performed by FM team for locating the facilities during the shadowing process of the research team in the hospital.

In the BIM model, integration of various types of drawings, 3D visualization of building components, and use of search and filter options can highly facilitate the locating process of different building components [5]. In this situation, FM crew can locate various components of the hospital building by navigating a prepared BIM model and searching for the identification number of different building components. No trial-and-error demolition experiences are required anymore;

- New equipment layout and installation management

Layout and installation management of new medical equipment purchased for the hospital is one responsibility of FM team. Selecting an adequate moving route, finding a proper location, and installing largesized equipment are quite challenging for FM team in the hospital. By using BIM model, it is possible to visualize different spaces and their specifications in $3 \mathrm{D}$ view. It allows $\mathrm{FM}$ crew to check different possible moving routes and installation scenarios to find the best possible choices and to avoid the trial-and-error approach. Furthermore, use of BIM helps the FM team more easily involves related medical personnel who are more familiar with new equipment's operational requirements in this process to find the best possible layout;

\section{- Coordination of FM staff}

FM crew needs to access a wide range of information about target facilities to conduct their maintenance, repair, replacement, and inspection activities. Currently, for more complicated FM activities that require coordination of several FM team members, they form coordination meetings. The coordination team discuss different aspects of the work by sharing past experiences and understanding about the facility and outlining work steps of each team member on pieces of papers. Use of $3 \mathrm{D}$ views provided by BIM models facilitates this coordination by demonstrating different aspects of the target facilities and assisting communication of team members [39];

- Communication with medical and other nontechnical personnel

Frequently, FM team members receive requests from different non-technical personnel including managers, physicians, nurses, and administrative staff that are neither feasible nor applicable due to the technical limitations. Explaining these limitations to the hospital personnel is a big and timeconsuming issue for the FM team and it is often seen as an unacceptable excuse by the hospital personnel. Use of 2D models usually does not help since FM team members are not comfortable working with them. Furthermore, they are barely understandable for non-technical staff. From this perspective, FM crew can use $3 \mathrm{D}$ views provided by the BIM model to explain existing limitations and embrace nontechnical staff for finding alternative solutions;

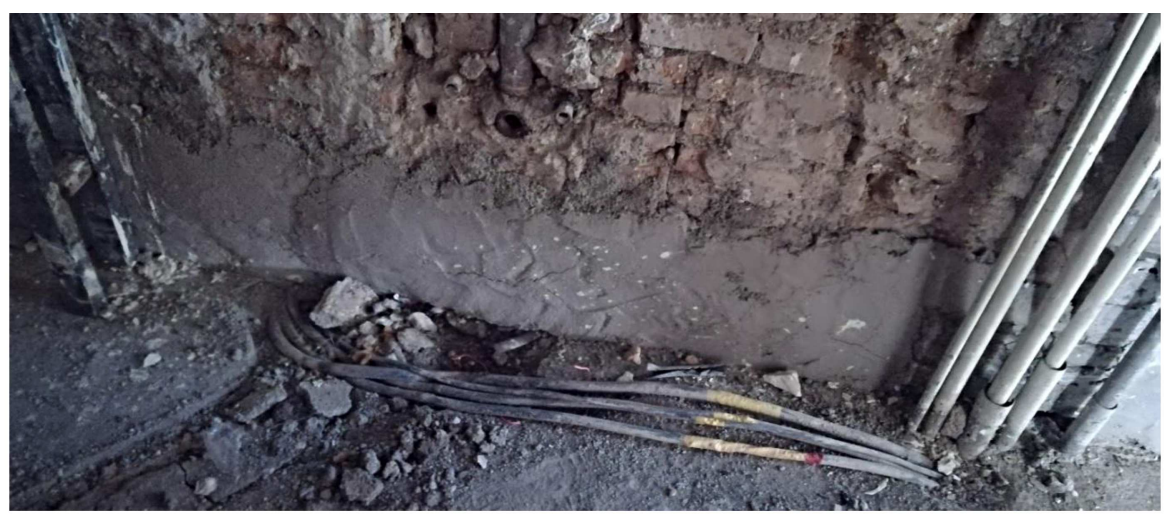

Figure 3. Wall and ceiling demolition for locating the Mechanical, Electrical, and Plumbing (MEP) installations. 


\section{- Training contractors and personnel} The diversity of facilities used in hospital buildings necessitates the use of external contractors who provide different types of FM services. All these contractors require a proper understanding of different parts of the hospital buildings. They need to receive orientations about different parts of the hospital and get trained by the FM team, which overall is in charge of the hospital FM. Furthermore, in the following three situations, training becomes important for FM team members as well [5]:

1. Hiring a new FM staff member: If a new member is hired in the FM team, the new member must be acquainted with the work processes, MEP systems, hospital equipment, and facilities;

2. Changing the work processes: If the work process in a sector or department undergoes serious changes, then these changes can result from the introduction of a new instruction or standard;

3. Installing new equipment and facilities: When new equipment or facilities are installed in the hospital, FM team members need to be trained in accordance with the new equipment requirements.

The current training process is conducted without any auxiliary tool involved by directly taking trainees to locations of various facilities and explaining related information to the trainee, which is very time-consuming. However, through the $3 \mathrm{D}$ navigations provided by BIM models, the trainee can become familiar with specifications of many facilities and see the required information. In addition, they can refer to the BIM model whenever maintenance and repair activities are assigned to them;

\section{- Emergency management}

In case of emergency situations, e.g., earthquake, fire, and thunderstorm, quick access to the hospital building information is vital to promptly bring the situation under control and help the ones in need. Currently, the Hasheminejad Hospital building's drawings are stored inside the hospital and in paper formats, which can easily become inaccessible in case of emergency. Use of BIM models that could also be stored in different MOHME's computers minimizes the risk of losing access to the hospital building's model in case of emergency. Another potential problem that the Hasheminejad Hospital faces is lack of emergency plans and preparedness, which can substantially aggravate the hospital in case of emergency. It is proposed that an emergency committee including different stakeholders in the hospital is formed and regular emergency coordination meeting is held. A representative of FM team should attend the meetings and walk committee members through different parts of the hospital buildings using the developed BIM model during the development of operational emergency response plans. BIM models are also used for conducting emergency training sessions, emergency tests, identifying unsafe areas, and mounting emergency signs and alerts in proper locations of the hospital building.

\subsection{Pilot implementation of the proposed improvements}

In order to test the applicability of the proposed FM improvements, they were applied to the surgical department of Hasheminejad Hospital located on the first floor with seven operating rooms and nine recovery beds. The surgical department was selected since it had a complex set of highly sensitive facilities to be operated and maintained [56]. Furthermore, fairly accurate as-built 2D drawings to be used for BIM model developments are available. Several modification plans were made to this department for near future which could benefit from the proposed improved capabilities of BIM. The department's ventilation system did not allow different surgical rooms to independently adjust their temperatures according to the specific needs and conditions of patients. Besides, the ventilation system was also crucial to preventing the transmission of the airborne infection to the patients [57]. Upgrading the ventilation system to an independently adjustable system was desired. Furthermore, all entries to and exits from this department were made through the only existing door at the department, which did not properly support the traffic. No emergency exit was also built for the department. Building a new door for this department that could facilitate better traffic management and be used for the emergency situations was also another planned modification.

The BIM model of the surgical department was developed in Revit 2017 software by a collaborating drafting company based on 2D architectural and MEP CAD drawings with input from the FM team (Figure 4). In order to evaluate the applicability of the proposed improvements in the FM processes, the developed BIM model and its navigation capability were presented to the FM team members on both computer screen and papers (Figure 5). Implementation of each proposed improvement in FM processes was then reviewed by FM team members. The team was quite welcoming and positive about the applicability and benefits of the proposed improvements that could bring to the FM processes of the hospital. In an exercise, the BIM model was used for locating the best place for the second door of the surgical department by involving several other stakeholders to help them determine the location of the door. In another practice, FM team members were encouraged to use the model to analyze the ventilation system and air channels and assess required modifications to meet the patients' needs. 


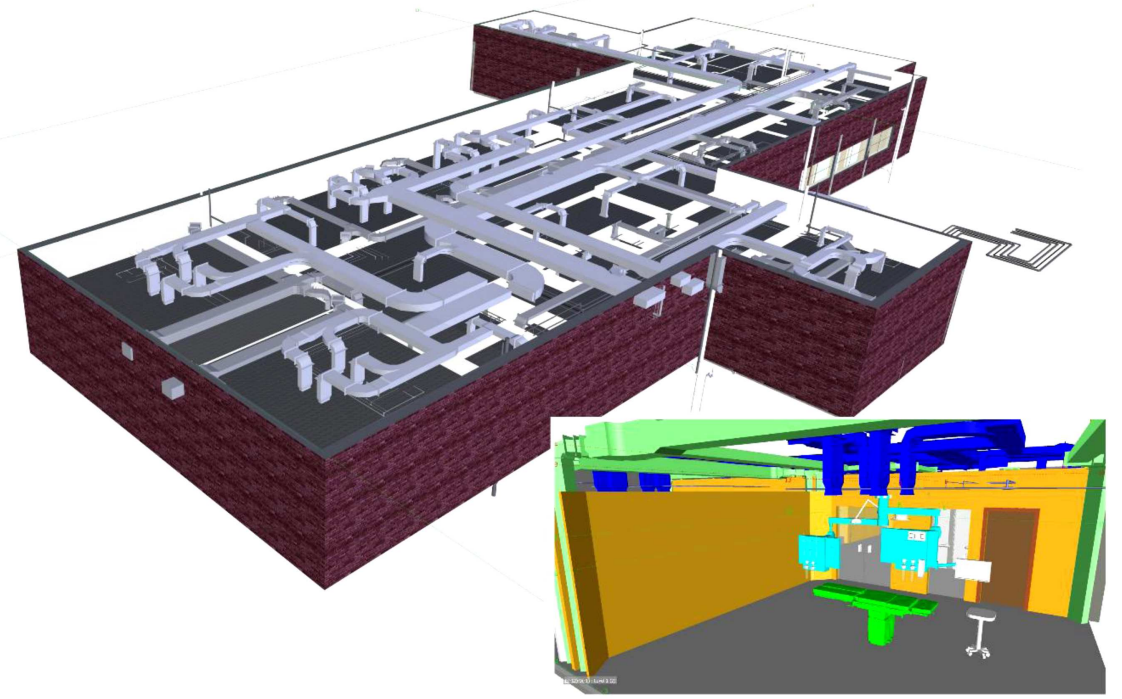

Figure 4. 3D view of the Building Information Modeling (BIM) model of the surgical department.

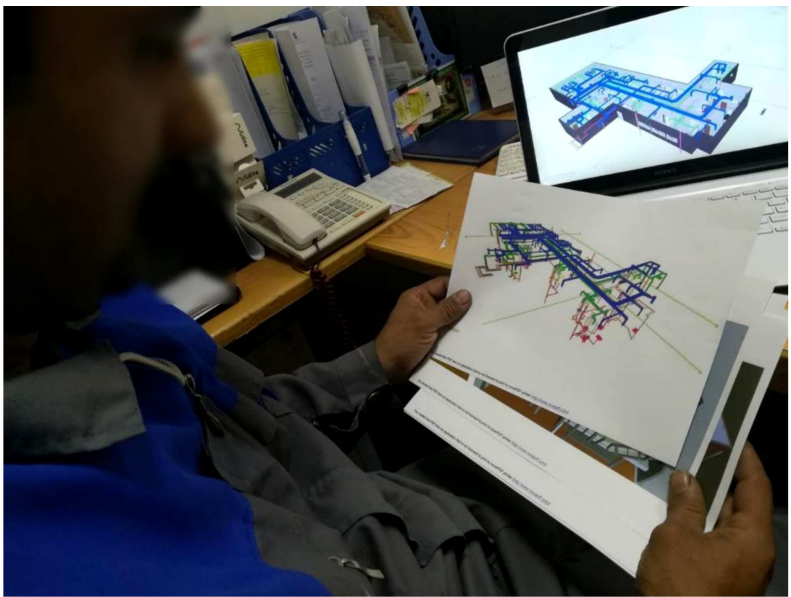

Figure 5. 3D views and navigation feature of the developed Building Information Modeling (BIM) models of surgical department to the Facility Management (FM) team members.

\section{Implementation architecture}

Since the nature of activities conducted in FM processes is quite different from those implemented in the design and construction of buildings, integration of BIM technologies in FM processes requires different implementation architectures than design and construction phases [58]. Here, we divided the implementation architecture of BIM in FM processes into the three following main parts: 1) defining applicable information items of BIM models for FM processes, 2) providing proper platforms to support BIM models for different staff working at different levels of the FM organization in different Public Hospitals, and 3) determining the methods in BIM software and operational data created in FM processes which were updated and maintained over the building's lifecycle. Different parts of the implementation architecture were recommended according to the specific condition identified for the public hospitals in the country and recent achievements reported in the literature.

In the first part of the BIM implementation architecture, applicable information items of BIM models for FM processes were determined. Many practitioners adopted COBIE standard in their BIM-based FM processes (e.g. [35-37]). However, since the use of BIM in FM processes in many cases happens with no past records of BIM, many researchers prefer using a customized data structure for integrating BIM in FM processes [33]. Meanwhile, a review of different related research efforts indicated that a wide range of tools were used for linking BIM and FM computer software (or CMMS) while the spreadsheets and thirdparty middleware (e.g., EcoDomus, Onuma Systems, and FM Interact) were the two main approaches adopted [21]. IT and engineering background weaknesses of the current FM crews in the public hospitals and budgetary limitations of public hospitals were the main constraints considered for the recommended architecture. From this perspective, holding expensive long-term training programs for the current FM crews or hiring new high-paid qualified FM personnel able to work with BIM models were discarded for the initial implementation. Therefore, in the initial stage of BIM implementation, it was recommended that minimum changes were made to the current organization and minimum possible information items were added to the BIM models. Maintenance operations applied to various hospital facilities identified in the $3 \mathrm{D}$ models could be recorded in the existing CMMS using the same identification numbers. Nevertheless, gradually, inte- 
gration level of FM processes with the BIM models may increase as the BIM maturity level of the organization increases [29].

The rapid growth and publicity of high-speed internet and the distributed nature of building components have encouraged major BIM software developers and many researchers (e.g. [58-60]) to develop webbased BIM 3D navigation platforms run on portable smartphones and tablets. In addition to the facilitated use of $3 \mathrm{D}$ models in this approach, the dependency of FM processes on the expensive standalone BIM software programs installed on high-performance desktop computers is reduced and multi-purpose and widely accessible smartphones and tablets take the place. In most public hospitals, currently available computers and high-speed internet connections can support the web-based approach. Use of this web-based approach was recommended in the second part of the implementation architecture.

For the public hospitals, specific instructions and mandates are set by the government to input FM operational data through currently developed CMMS, which are supposed to be followed in the third part of the recommended implementation architecture. Furthermore, it is recommended that MOHME centrally maintain the most updated BIM models and provide web-based access to the $3 \mathrm{D}$ views of the updated BIM models to the hospitals. This approach takes the advantage of the centralized management and ownership of public hospitals by MOHME and helps Public Hospitals overcome IT and engineering background weaknesses of FM crews. Figure 6 represents the

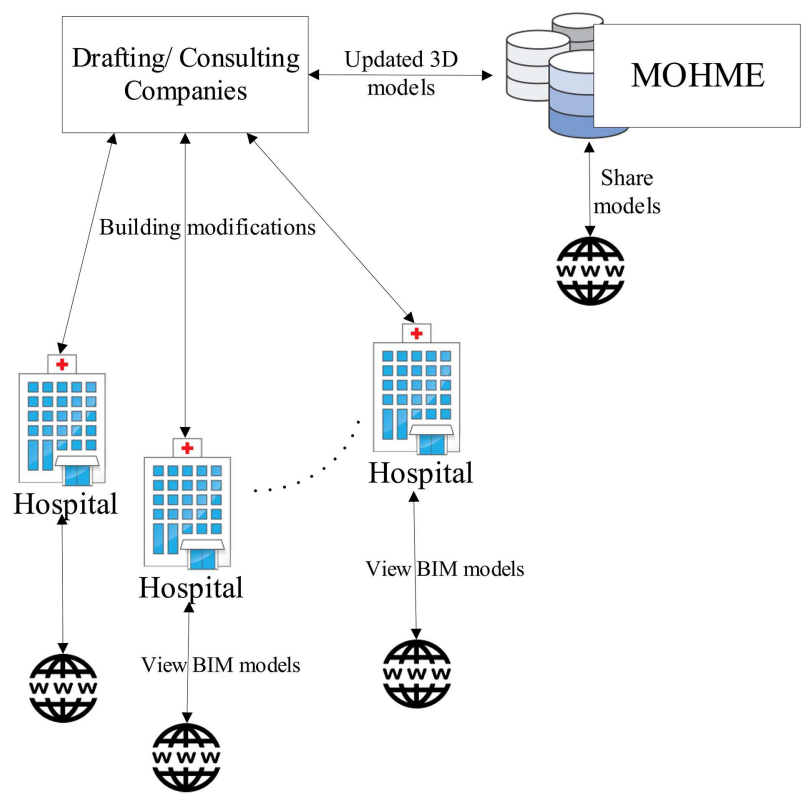

Figure 6. Recommended implementation architecture of Building Information Modeling (BIM)-based Facility Management (FM) of public hospitals. recommended implementation architecture of the BIMbased FM of public hospitals.

\section{Conclusion}

In this research, the applicability of various identified improvements that Building Information Modeling (BIM) can bring to the Facility Management (FM) processes of public hospitals in Iran was investigated. Data were collected from different aspects of Iran's public health system and a case study of Hasheminejad Public Hospital in Tehran, Iran was conducted. Budgetary constraints and low IT and engineering background level of FM crew were the two main criteria identified for the proposed BIM-based FM process. It was argued that use of capability of BIM models in conjunction with the existing Computerized Maintenance Management System (CMMS) would improve the FM processes in terms of locating building components, coordination of FM, layout planning of new facilities, communication with medical and nontechnical hospital personnel, training new FM crew, and emergency management. Applicability of the proposed improvements to the pilot BIM model of the hospital's surgical department was evaluated and then, incorporating FM team members in the implementation of different improvements was proposed. The proposed improvements were welcomed by FM crew and they acknowledged the viability of the model in the FM process. Finally, to apply the proposed improvements to FM processes of different public hospitals in the country, an implementation architecture that would suit the current organizational structure of public health system and consider its main constraints was recommended.

Forcing drastic changes and high investment costs were two main constraints frequently seen during the implementation process of new IT-based systems [60]. Although various BIM features could improve FM performance, it was expected that sudden changes to the processes resulted in high resistance from different stakeholders as well as in slowing down or even blocking the implementation of the new processes. To avoid facing this problem, minimal changes to the current FM processes were considered.

This research is the first study to have incorporated BIM in the FM processes of the network of hospitals and it opens a new era for future improvement of FM processes of the network of public or private hospitals. With the current extent of FM activities in the aging public hospital buildings in Iran, the proposed implementation architecture can bring considerable saving to HOHME's costs in a long run. Furthermore, it should be noted that the proposed improvements in the research are only the beginning of the long way of incorporating BIM in the FM of public hospitals. 
Advanced features of BIM can gradually merge with the FM processes, while BIM culture is built among FM team members and other hospitals' personnel. Of course, before engagement of these new features in public hospitals' FM processes, further research needs to be conducted to analyze feedback from the implementation of the currently proposed improvements and plan for implementation of new features. Results achieved in this study are presented to Ministry Of Health and Medical Education (MOHME) decisionmakers to cajole them into applying the proposed improvements to the public hospitals.

\section{Acknowledgement}

We would like to express our appreciation to Farda Fan Pars Engineering Consultant Co. which helped us with development of BIM models used in the case study.

\section{References}

1. HPC (Health Policy Commission) "2013 cost trend report", Massachusetts Government, Health Policy Commission, Annual report, 2014, available at: http://www.mass.gov/anf/docs/hpc/2013-costtrends-report-full-report.pdf (accessed 20 August 2017) (2014).

2. Kalman, N., Hammill, B., Schulman, K., et al. "Hospital overhead costs: the neglected driver of health care spending?", Journal of Health Care Finance, 41(4), pp. 1-15 (2015).

3. World Health Organization "World health statistics 2015", World Health Organization (2015).

4. Sebastian, R. "Changing roles of the clients, architects and contractors through BIM", Engineering, Construction and Architectural Management, 18, pp. 176187 (2011).

5. Becerik-gerber, B., Jazizadeh, F., LI, N., and Calis, G. "Application areas and data requirements for BIMenabled facilities management", Journal of Construction Engineering and Management, 138, pp. 431-442 (2011).

6. Gallaher, M.P., O'Connor, A.C., Dettbarn, Jr., et al., Cost Analysis of Inadequate Interoperability in the US Capital Facilities Industry, National Institute of Standards and Technology (NIST), Maryland (2004).

7. Lucas, J., Bulbul, T., Thabet, W., et al. "Case analysis to identify information links between facility management and healthcare delivery information in a hospital setting", Journal of Architectural Engineering, 19, pp. 134-145 (2012).

8. Yalcinkaya, M. and Singh, V. "Building information modeling (BIM) for facilities management-literature review and future needs", IFIP International Conference on Product Lifecycle Management, Springer, Berlin, Heidelberg, pp. 1-10 (2014).
9. Wang, Z., Bulbul, T., and Lucas, J. "A case study of BIM-based model adaptation for healthcare facility management-information needs analysis", International Workshop on Computing in Civil Engineering, pp. 395-402 (2015).

10. Liu, R. and Issa, R. "Issues in BIM for facility management from industry practitioners' perspectives", Computing in Civil Engineering, Los Angeles, California, pp. 411-418 (2013).

11. Lee, S.K., An, H.K., and Yu, J.H. "An extension of the technology acceptance model for BIM-based FM", Construction Research Congress, West Lafayette, Indiana, pp. 602-611 (2012).

12. Bråthen, K., Bråthen, K., and Moum, A. "Bridging the gap: bringing BIM to construction workers", Engineering, Construction and Architectural Management, 23, pp. 751-764 (2016).

13. Jafari, M., Rashidian, A., Abolhasani, F., et al. "Space or no space for managing public hospitals; a qualitative study of hospital autonomy in Iran", The International Journal of Health Planning and Management, 26(3), pp. 121-127 (2011).

14. Farzadi, F., Maftoon, F., Aeenparast, A., et al. "Determinants of satisfaction with health care system: A population-based study from Iran", Journal of Payesh, 10(3), pp. 323-330 (2011).

15. Maharlouei, N., Akbari, M., Akbari, M., et al. "Socioeconomic status and satisfaction with public healthcare system in Iran", International Journal of Community Based Nursing and Midwifery, 5, p. 22 (2017).

16. IFMA (International Facility Management Association) "What is Facility Management?" available at: http://ifmahouston.org/content.php? page =What_is Facility_Management (accessed 15 October 2017) (2017).

17. Wang, S., Intelligent Buildings and Building Automation, Taylor \& Francis, London and New York (2009).

18. Lucas, J., Bulbul, T., and Thabet, W. "An objectoriented model to support healthcare facility information management", Automation in Construction, 31, pp. 281-291 (2013).

19. Yousefli, Z., Nasiri, F., and Moselhi, O. "Healthcare facilities maintenance management: a literature review", Journal of Facilities Management, 15(4), pp. 352-375 (2017).

20. Kassem, M., Kelly, G., Dawood, N., et al. "BIM in facilities management applications: a case study of a large university complex", Built Environment Project and Asset Management, 5(3), pp. 261-277 (2015).

21. Thabet, W. and Lucas, J. "Asset data handover for a large educational institution: Case-study approach", Journal of Construction Engineering and Management, 143(11), 05017017 (2017).

22. Ballesty, S., Mitchell, J., Drogemuller, R., et al., Adopting BIM for Facilities Management: Solutions for Managing the Sydney Opera House, Cooperative Research Centre (CRC) for Construction Innovation, Brisbane, Australia (2007). 
23. Codinhoto, R., Kiviniemi, A., Kemmer, S., et al., Manchester Town Hall Complex, University of Salford, Manchester (2013).

24. Chen, C., Dib, H., and Lasker, G. "Benefits of implementing building information modeling for healthcare facility commissioning", Proceedings of the 2011 ASCE International Workshop on Computing in Civil Engineering, June 19-22, 2011, Miami, Florida, USA, pp. $578-585$ (2011).

25. 25 Irizarry, J., Gheisari, M., Williams, G., et al. "Ambient intelligence environments for accessing building information: A healthcare facility management scenario", Facilities, 32(3/4), pp. 120-138 (2014).

26. Lavy, S. and Saxena, N. "Quantifying the effect of using BIM and COBie for facility management on work order processing times: A case study", International Journal of Facility Management, 6(1), Retrieved November 2, 2015, from: http:// ijfm.net/index.php/ijfm/article/view/133 (2015).

27. Terreno, S., Anumba, C., Gannon, E., et al. "The benefits of BIM integration with facilities management: A preliminary case study", Computing in Civil Engineering 2015, pp. 675-683 (2015).

28. Love, P.E.D., Matthews, J., and Lockley. S. "BIM for built asset management", Built Environment Project and Asset Management 5.3 (2015).

29. Edirisinghe, R., London, K.A., Kalutara, P., et al. "Building information modelling for facility management: are we there yet?", Engineering, Construction and Architectural Management, 24(6), pp. 1119-1154 (2017).

30. building Smart "IFC overview summary", building Smart, available at: http://www.buildingsmarttech.org/specifications/ifc-overview (accessed 8 August 2018) (2018).

31. ISO "Industry Foundation Classes (IFC) for data sharing in the construction and facility management industries", International Organization for Standardization (ISO), ISO 16739:2013. Available at: https://www.iso.org/standard/51622.html (2013).

32. Wetzel, E.M. and Thabet, W.Y. "The use of a BIMbased framework to support safe facility management processes", Automation in Construction, 60, pp. 12-24 (2015).

33. Pärn, E.A., Edward, D.J., and Sing, M.C.P. "The building information modelling trajectory in facilities management: A review", Automation in Construction, 75, pp. $45-55$ (2017).

34. East, E.W. "Construction operations building information exchange (COBIE) - requirements definition and pilot implementation standard", U.S. Army Corps of Engineers, Washington D.C. (2007).

35. Nisbet, N. "COBIE data import/export interoperability with the MAXIMO computerized maintenance management system", Construction Engineering Research Laboratory (2008).
36. Patacas, J., Dawood, N., Vukovic, V., et al. "Evaluating IFC and COBie in specific facility management application: the case of asset register creation and service life planning", Journal of Information Technology in Construction, 20, pp. 313-331 (2015).

37. Lin, Y.C., Chen, Y.P., Huang, W.T., et al. "Developing the framework of BIM execution plan for facility management", Journal of Buildings, 6(1), pp. 1-14 (2016).

38. Yin, X., Wonka, P., and Razdan, A. "Generating 3d building models from architectural drawings: A survey", IEEE Computer Graphics and Applications, 29(1), pp. 20-30 (2009).

39. Eastman, C.M., Eastman, C., Teicholz, P., et al., BIM handbook: A Guide to Building Information Modeling for Owners, Managers, Designers, Engineers and Contractors, John Wiley \& Sons, New Jersey (2011).

40. Brilakis, I., Lourakis, M., Sacks, R., Savarese, S., Christodoulou, S., Teizer, J., and Makhmalbaf, A. "Toward automated generation of parametric BIMs based on hybrid video and laser scanning data", Advanced Engineering Informatics, 24, pp. 456-465 (2010).

41. Volk, R., Stengel, J., and Schultmann, F. "Building Information Modeling (BIM) for existing buildingsLiterature review and future needs", Automation in Construction, 38, pp. 109-127 (2014).

42. Mahamadu, A.M., Mahdjoubi, L., and Booth, C. "Challenges to BIM-cloud integration: Implication of security issues on secure collaboration", IEEE 5th International Conference on Cloud Computing Technology and Science (CloudCom), Bristol, UK, pp. 209214 (2013).

43. Gu, N. and London, K. "Understanding and facilitating BIM adoption in the AEC industry", Automation in Construction, 19, pp. 988-999 (2010).

44. Gheisari, M. and Irizarry, J. "Investigating human and technological requirements for successful implementation of a BIM-based mobile augmented reality environment in facility management practices", Journal of Facilities, 34(1/2), pp. 69-84 (2016).

45. Motamedi, A., Soltani, M.M., and Hammad, A. "Localization of RFID-equipped assets during the operation phase of facilities", Journal of Advanced Engineering Informatics, 27(4), pp. 566-579 (2013).

46. Lin, Y.C. and Su, Y.C. "Developing mobile- and BIMbased integrated visual facility maintenance management system", Hindawi Publishing Corporation, The Scientific World Journal, 2013, Article ID 124249, 10 pages (2013).

47. World Health Organization, Health System Profile, Islamic Republic of Iran, Regional Health Systems Observatory, WHO Eastern Mediterranean Regional Office (2006).

48. Mehrdad, R. "Health system in Iran", JMAJ, 52, pp. 69-73 (2009). 
49. Rezaei, S., Matin, B.K., Karyani, A.K., et al. "Distribution of physicians and hospital beds based on Gini coefficient and Lorenz curve: A national survey", Journal of Kermanshah University of Medical Sciences, 20(1), pp. 30-36 (2016).

50. Hosseini, N. "Tehran's old hospitals", available at: http://www.mehrnews.com/news/2578756 (2015).

51. MOHME "Resistance Economy by Implementing Comprehensive Maintenance Management System" Minstry of Health and Medical Education (MOHME), News Center, News Number 157392 (2017).

52. Succar, B. "Building information modelling maturity matrix", In Handbook of Research on Building Information Modeling and Construction Informatics: Concepts and Technologies, pp. 65-103, IGI Global (2010).

53. Teicholz, P., BIM for Facility Managers, John Wiley \& Sons, New Jersey (2013).

54. Dong, B., O'Neill, Z., and Li, Z. "A BIM-enabled information infrastructure for building energy fault detection and diagnostics", Automation in Construction, 44, pp. 197-211 (2014).

55. Haghi, M., Fatemi Ghomi, S.M.T., and HooshangiTabrizi, P. "A novel deterministic model for simultaneous weekly assignment and scheduling decisionmaking in operating theaters", Scientia Iranica, 24(4), pp. 2035-2049 (2017).

56. Eslami, J., Abbassi, A., and Saidi, M.H. "Numerical simulation of the effect of visitor's movement on bacteria-carrying particles distribution in hospital isolation room", Scientia Iranica. Transaction B, Mechanical Engineering, 24(3), p. 1160 (2017).

57. Lee, W.L., Tsai, M.H., and Yang, C.H. "V3DM+: BIM interactive collaboration system for facility management", Visualization in Engineering, 4, (1), p. 5 (2016).
58. Jeong, W. and Yan, W. "A web-based communication platform for building information models", 47th International Conference of the Architectural Science Association, Hong Kong, pp. 365-374 (2013).

59. Nakama, Y., Onishi, Y., and Iki, K. "Development of building information management system using BIM toward strategic building operation and maintenance", 20th International Conference on Computer-Aided Architectural Design Research in Asia CAADRIA, Daegu, Korea, pp. 397-406 (2015).

60. Migilinskas, D., Popov, V., Juocevicius, V. et al "The benefits, obstacles and problems of practical BIM implementation", Procedia Engineering, 57, pp. 767774 (2013).

\section{Biographies}

Amin Alvanchi has been an Assistant Professor at the Department of Civil Engineering, with specialization in construction engineering and management, at the Sharif University of Technology, Tehran, Iran since February 2013. He has received his PhD in Construction Engineering and Management from the University of Alberta, Canada in 2011. His area of research focuses on building information modeling, construction project management, construction operation simulation, and contract administration.

Abolfazl Seyrfar is an MSc graduate student at Construction Engineering Management, the Sharif University of Technology since September 2015. He has recently been admitted continuing his studies at the $\mathrm{PhD}$ level at the University of Illinois, Chicago, United States. 